\title{
Características de carcaça, componentes não-carcaça e morfometria em ovinos submetidos a diferentes estratégias de suplementação
}

\section{Carcass characteristics, non-carcass components and morphometry in sheep submitted to different supplementation strategies}

\author{
Dorismar David Alves ${ }^{1 *}$; Luciano Macena de Araújo ${ }^{2}$; \\ Hélida Christhine de Freitas Monteiro ${ }^{1}$; Fernando de Paula Leonel ${ }^{3}$; \\ Fredson Vieira e Silva ${ }^{1}$; Danilo Antunes Simões ${ }^{4}$; Weiber da Costa Gonçalves ${ }^{5}$; \\ Lara Maria Santos Brant ${ }^{5}$
}

\section{Resumo}

O objetivo da pesquisa foi avaliar as características de carcaça, os componentes não-carcaça e a morfometria em ovinos submetidos a diferentes estratégias de suplementação. Utilizaram-se 24 ovinos machos inteiros oriundos de cruzamentos da raça Santa Inês com animais sem raça definida (SRD), com peso vivo médio inicial de $20,58 \mathrm{~kg}$. Os animais foram distribuídos em quatro tratamentos em um delineamento inteiramente casualizado, com seis repetições por tratamento. O período experimental teve duração de 83 dias, sendo 20 dias de adaptação ao ambiente e às dietas e 63 dias para coleta de dados. Todos os animais receberam ad libitum feno de capim-tifton 85 e os tratamentos consistiram no oferecimento de distintos suplementos: mineral; mineral com ureia; proteinado; concentrado. $\mathrm{O}$ suplemento concentrado possibilitou maiores peso vivo final, ganho médio diário em peso vivo, peso de carcaça quente, rendimento de carcaça quente em relação ao peso vivo final e rendimento de cortes cárneos, em quilogramas, em relação aos suplementos mineral, mineral com ureia e proteinado. Os tratamentos não influenciaram os percentuais do componentes não-carcaça. O suplemento concentrado resultou em maior largura de peito e perímetro de perna, medidas mensuradas in vivo e na carcaça, respectivamente. As mensurações morfométricas na carcaça podem ser utilizadas com maior precisão na predição do ganho médio diário em peso vivo e do rendimento de carcaça quente que medidas morfométricas in vivo, destacando-se a largura de tórax e os perímetros de garupa e de perna.

Palavras-chave: Comprimento de carcaça, mestiços, órgãos internos, rendimento de carcaça, Santa Inês

\begin{abstract}
The objective of the research was to evaluate carcass characteristics, non-carcass components and morphometry in sheep subjected to different supplementation strategies. It was used 24 male sheep, not emasculated, products crossing the Santa Inês breed with animals without definition of race (WDR), with average weight of $20.58 \mathrm{~kg}$. The animals were distributed in four treatments in a completely randomized
\end{abstract}

\footnotetext{
${ }^{1}$ Profs. da Universidade Estadual de Montes Claros, UNIMONTES, Campus Janaúba, Janaúba, MG. E-mail: dorismar.alves@ unimontes.br; helida.monteiro@unimontes.br; fredson.silva@unimontes.br

${ }^{2}$ M.e em Zootecnia, UNIMONTES, Janaúba, MG. E-mail: lucianomacena@hotmail.com

${ }^{3}$ Prof. da Universidade Federal de São João del Rei, UFSJ, São João del-Rei, MG. E-mail: fernandoleonel@ufsj.edu.br

${ }^{4}$ Eng $^{\mathrm{o}} \mathrm{Agr}^{\circ}$ da UNIMONTES, Janaúba, MG. E-mail: daniloantunes@ymail.com

${ }^{5}$ Discentes do curso de Mestrado do Programa de Pós-Graduação em Zootecnia, UNIMONTES, Campus Janaúba, Janaúba, MG. E-mail:weioz@hotmail.com; lara_brantt@hotmail.com

* Autor para correspondência
} 
design with six replicates per treatment. The experimental period lasted 83 days, 20 days of adaptation to environment and diet and 63 days of the experiment itself. All animals were fed ad libitum hay and Tifton 85 have been treated with different supplements: Treatment Mineral = mineral supplement; Treatment mineral associated with urea $=$ mineral supplement + urea + ammonium sulfate; Treatment protein $=$ protein supplement; Treatment concentrate $=$ concentrate supplement. The concentrated treatment provides higher final live weight, average daily gain in live weight, hot carcass weight, carcass yield in relation to the final live weight and yield of meat, in kilograms, compared to treatments mineral, mineral associated with urea and protein. The treatments did not influence the percentage of non-carcass components. The concentrated treatment results in increased width of the chest and leg circumference measured in vivo and measures in the housing, respectively. The morphometric measurements on the carcass can be used to more accurately predict the average daily gain in live weight and hot carcass yield that morphometric measurements in vivo, emphasizing the width of the chest and perimeters of hip and leg.

Key words: Carcass length crossbred internal organs, carcass, Santa Ines

\section{Introdução}

Qualidade da carne, rendimento e composição da carcaça ovina constituem elementos imprescindíveis na conquista e/ou ampliação de mercados. Dentre os diversos fatores que influenciam as características de carcaça e a composição corporal dos animais, pode-se destacar a suplementação de ovinos, que aliada a outros fatores, como genética e sanidade, pode contribuir no aumento da rentabilidade dos sistemas de produção da carne ovina.

A suplementação de ovinos em pastejo surge como alternativa para atenuar as variações na produção de forragem ao longo da estação de pastejo ou durante o ano, na expectativa de suprir a deficiência em quantidade ou qualidade da forragem, aventando-se a possibilidade de melhoria do desempenho animal e da oferta de animais para abate, especialmente durante o período de estiagem, que constitui a época crítica de oferta de animais prontos para serem abatidos.

A avaliação do rendimento de carcaça e das proporções dos cortes comercializáveis, dentre outros fatores, constituem importantes parâmetros na determinação dos índices de rentabilidade dos diversos segmentos envolvidos na cadeia produtiva da carne ovina. Segundo Siqueira (2000) e Martinez et al. (2001), os maiores rendimentos de carcaça podem estar associados à baixa porcentagem de componentes não-constituintes da carcaça e/ou à maior deposição de tecido adiposo nos animais suplementados, bem como à semelhança no peso do conteúdo gastrintestinal.

Apesar da comercialização de ovinos se basear apenas na observação do peso dos animais, para melhor interação entre os interesses de produtores e consumidores, é necessário o conhecimento da composição percentual dos cortes e de outras partes que compõem o peso dos animais e que caracterizam a qualidade do produto (FURUSHOGARCIA et al., 2003). Em adição, Ruiz de Huidobro e Cañeque (1994) afirmaram que os distintos cortes que compõem a carcaça possuem diferentes valores econômicos e a sua proporção constitui importante índice para avaliação da qualidade comercial da carcaça. Dessa forma, o rendimento dos diferentes cortes comerciais da carcaça são parâmetros importantes para direcionar sistemas de alimentação que venham obter cordeiros jovens em terminação.

Não obstante à importância da avaliação da carcaça e dos cortes, deve-se ressaltar que os componentes não pertencentes à carcaça podem representar até $60 \%$ do peso do ovino e, com a valorização comercial que somam à carcaça, poderão proporcionar uma fonte de renda alternativa para o ovinocultor (CARVALHO et al., 2007). No Nordeste do Brasil, os componentes não-carcaça que integram a parte do trato gastrintestinal mais alguns órgãos, conhecidos como buchada, são 
comercializados em quilograma e constituem 30\% do valor do animal, podendo ser utilizados como fonte adicional de renda (SILVA SOBRINHO, 2001).

Para complementar a avaliação do desempenho animal no sistema de produção de carne, as características qualitativas e quantitativas da carcaça são de fundamental importância. As medidas realizadas na carcaça permitem comparações entre tipos raciais, pesos e idades ao abate, sistemas de alimentação e, também, o estabelecimento de correlações com outras medidas ou com os tecidos constituintes da carcaça, para possibilitar a estimativa de suas características físicas (SILVA; PIRES, 2000).

Além das avaliações feitas nos animais abatidos, medidas obtidas a partir do animal vivo, como comprimento corporal, alturas do anterior e posterior, perímetro torácico e largura da garupa, associadas à avaliação subjetiva da condição corporal e conformação, constituem ferramentas importantes na determinação do momento ideal de abate. Embora essas medidas não possam, isoladamente, definir as características da carcaça, permitem predizer algumas características produtivas como peso, rendimento e conformação da carcaça, assim como o rendimento dos cortes (PINHEIRO et al., 2007).

Face às considerações feitas, foram avaliadas as características de carcaça, componentes não-carcaça e morfometria em ovinos submetidos a diferentes estratégias de suplementação.

\section{Material e Métodos}

O experimento foi conduzido na Fazenda Experimental da Universidade Estadual de Montes Claros - UNIMONTES, na cidade de Janaúba, região norte de Minas Gerais, entre os dias 23 de março e 14 de junho de 2011.

Utilizaram-se 24 ovinos machos inteiros oriundos de cruzamentos da raça Santa Inês com animais sem raça definida (SRD), com peso vivo médio inicial de $20,58 \mathrm{~kg}$. Os animais foram distribuídos em quatro tratamentos em um delineamento inteiramente casualizado, com seis repetições por tratamento.

Os animais foram alojados em baias individuais de $3 \mathrm{~m}^{2}$ cobertas com sombrite, providas de comedouros e bebedouros. O período experimental teve duração de 83 dias, sendo 20 dias de adaptação ao ambiente e às dietas e 63 dias para coleta de dados. Antes do período de adaptação, os animais foram submetidos ao controle de endo e ectoparasitos e identificados com colares numéricos. Durante a adaptação os animais receberam a mesma ração oferecida no período experimental, de acordo com os tratamentos. Ao término do período de adaptação, todos os animais foram submetidos a um período de jejum de 16 horas de água e alimentos, para posterior pesagem. Os valores ponderais dos animais foram anotados e se iniciou o período de coleta de dados propriamente dito, que foi dividido em três períodos de 21 dias.

Utilizou-se como volumoso o feno de capimtifton 85, armazenado há aproximadamente dois anos em galpões cobertos desde a fenação. Todos os animais receberam ad libitum o feno e os tratamentos consistiram no oferecimento de distintos suplementos: suplemento mineral; suplemento mineral com ureia; suplemento proteinado e suplemento concentrado.

O suplemento ureia consistiu da mistura de suplemento mineral com ureia e sulfato de amônio, nas concentrações de 60,36 e 4\%, respectivamente, fornecido ad libitum.

Utilizou-se suplemento proteinado comercial contendo na sua formulação farelo de soja, fubá de milho, cloreto de sódio, premix mineral concentrado, calcário calcítico, ureia pecuária e enxofre em pó e fornecido ad libitum.

A composição químico-bromatológica do feno de capim-tifton 85 e dos suplementos durante o período experimental é apresentada na Tabela 1. 
Tabela 1. Teores médios de matéria seca (MS), matéria orgânica (MO), proteína bruta (PB), fibra em detergente neutro (FDN), fibra em detergente ácido (FDA), extrato etéreo (EE) e matéria mineral (MM).

\begin{tabular}{lccccc}
\hline Alimento & MS (\%) & MM* & PB* & FDN* & EE* $^{*}$ \\
\hline Feno capim-tifton 85 & 92,26 & 10,11 & 11,20 & 73,97 & \\
Suplemento mineral & 98,22 & 100 & --- & -- & --- \\
Supl. mineral com ureia & 95,04 & 100 & 101,88 & -- & --- \\
Suplemento proteinado & 93,68 & 60,5 & 38,21 & 11,2 & 3,7 \\
Suplemento concentrado & 90,00 & 4,7 & 16,2 & 35,0 & 5,5 \\
\hline
\end{tabular}

*Valores expressos em porcentagem na matéria seca.

Fonte: Elaboração dos autores.

O suplemento concentrado, fornecido diariamente na base de $0,8 \%$ do peso vivo (base matéria natural), foi formulado com fubá de milho, farelo de soja, ureia pecuária, cloreto de sódio, calcário calcítico, fosfato bicálcico e premix mineral.

O feno foi fornecido duas vezes ao dia, observando-se a manutenção de sobras diárias entre 10 e $15 \%$ do oferecido, com base na matéria seca. Diariamente foi registrada a quantidade oferecida, e as sobras foram coletadas e pesadas semanalmente para determinar o consumo de nutrientes. A cada período de 21 dias, a contar do início do período de coleta de dados, amostras compostas proporcionais das sobras foram feitas por animal, para posteriores análises em laboratório. As determinações de matéria seca, matéria mineral, $\mathrm{N}$ total, extrato etéreo e fibra em detergente neutro dos alimentos oferecidos foram realizadas conforme metodologias descritas por Silva e Queiroz (2002)

Para acompanhar o desenvolvimento dos animais, foram efetuadas pesagens individuais, a cada 21 dias, com jejum prévio de 16 horas de água e alimentos. $\mathrm{Na}$ determinação do ganho em peso médio diário, utilizou-se o peso vivo final menos o peso vivo inicial, dividido pelos dias de duração do período experimental propriamente dito.

Após a pesagem final e imediatamente antes do abate dos animais, procedeu-se, com auxílio de uma régua antropométrica, as avaliações morfométricas in vivo de comprimento do corpo, comprimento horizontal do corpo, altura da cernelha, altura do sacro, altura do peito, altura do tórax, largura de peito, largura de íleo, largura de ísquio e perímetro de torácico, de acordo com Cezar e Sousa (2007).

$\mathrm{O}$ abate foi realizado por meio de atordoamento mecânico, utilizando-se uma pistola pneumática na região do osso occipital, com posterior sangria efetuada pela seção dos grandes vasos do pescoço. $\mathrm{O}$ sangue foi coletado e devidamente pesado. $\mathrm{Na}$ sequência do abate, após a sangria e esfola dos animais, foram removidos e pesados, separadamente, os componentes não-carcaça: couro, cauda, cabeça, pés, órgãos brancos (rúmen, retículo, omaso e abomaso, intestino delgado, intestino grosso), órgãos vermelhos (coração, fígado, rins, baço e pulmões) e aparas (conjunto composto por esôfago, traquéia, língua e aparelho reprodutor).

O peso corporal vazio (PCV) de cada animal foi determinado, após o abate, deduzindo-se do peso vivo em jejum (PVJ) o peso do conteúdo do trato gastrintestinal.

Após a separação dos componentes nãoconstituintes da carcaça, foi obtido o peso da carcaça quente (PCQ), que foi utilizado para estimar o rendimento verdadeiro (RV) e o rendimento biológico (RB), a partir das equações citadas por Silva et al. (2008):

$$
\begin{aligned}
& \mathrm{RV}(\%)=\mathrm{PCQ} / \mathrm{PVJ} \times 100 ; \\
& \mathrm{RB}(\%)=\mathrm{PCQ} / \mathrm{PCV} \times 100 .
\end{aligned}
$$

Em seguida, as carcaças foram resfriadas a 
$5^{\circ} \mathrm{C}$ durante 24 horas. Após esse período, foram realizadas as medidas morfométricas da carcaça (comprimento externo da carcaça, largura da garupa, largura do tórax, perímetro da garupa, perímetro de perna), segundo a proposição de Cezar e Sousa (2007). Na sequência, as carcaças foram divididas longitudinalmente em duas meias carcaças com auxílio de uma serra elétrica. $\mathrm{Na}$ meia carcaça esquerda foram realizadas as mensurações de comprimento interno da carcaça e comprimento da perna. Em seguida, a meia carcaça direita foi subdividida em seis regiões anatômicas, denominadas cortes comerciais, de acordo com Cezar e Sousa (2007):

Pescoço - metade das sete vértebras cervicais;

Paleta - obtido pela secção da região axilar, dos músculos que unem a escápula e o úmero na parte ventral do tórax tangente à coluna vertebral;

Costilhar - corte obtido pela secção entre as metades da primeira vértebra e última vértebra torácica, incluindo a região proximal e média das costelas;

Serrote - corte foi efetuado a partir de uma linha reta, com início no vazio até a articulação escapuloumeral, incluindo a região distal das costelas;

Lombo - corte realizado entre as metades da última vértebra torácica e a primeira lombar e outro entre a última lombar e primeira sacral;

Perna - obtida compreendendo a região sacral, o cíngulo pélvico e a perna, com secção no nível da articulação da última vértebra lombar e primeira sacral e na posição média dos ossos do tarso.

Os cortes foram pesados para cálculo dos seus rendimentos em relação ao peso da carcaça e, logo após, foram acondicionados em sacos plásticos e congelados $\mathrm{a}-12^{\circ} \mathrm{C}$.

O delineamento utilizado foi o inteiramente ao acaso distribuídos em quatro tratamentos com seis repetições. Utilizou-se o Sistema de Análises
Estatísticas e Genéticas - SAEG (UNIVERSIDADE FEDERAL DE VIÇOSA, 2000) para avaliação dos resultados, que foram submetidos à análise de variância e teste "F", sendo que as características que foram significativas em nível de 5\% foram submetidas ao teste de Student Newman Keuls (SNK), também em nível de 5\% de significância. As variáveis ganho médio diário, rendimento de carcaça quente em relação ao peso vivo e em relação ao peso de corpo vazio foram submetidas à análise de correlação de Pearson, em nível de 5\% de probabilidade pelo teste " $t$ ", com as variáveis morfométricas in vivo e na carcaça.

\section{Resultados e Discussão}

Observa-se na Tabela 2 que os tratamentos influenciaram no peso vivo final (PVF) e no ganho médio diário em peso vivo (GMD). Provavelmente o maior consumo de matéria seca ( $\mathrm{kg} / \mathrm{dia})$, associado ao maior aporte de proteína bruta (g/ dia) para os animais do tratamento concentrado, possam justificar parcialmente os resultados favoráveis de peso vivo final e ganho médio diário observados nesse tratamento. Tendo em vista o considerável valor de proteína bruta do feno $(11,2 \%)$ oferecido aos animais, bem como o fato dos suplementos mineral com ureia e proteinado não terem sido eficientes em aumentar o aporte de proteína na dieta, por apresentarem consumo reduzido (20 e $40 \mathrm{~g} /$ animal/dia, respectivamente), pode-se aventar a hipótese de que parte da proteína bruta da forragem estava indisponível ao aproveitamento pela microbiota ruminal e não sendo digeridos nos demais compartimentos digestivos dos animais, denotando a baixa qualidade do volumoso utilizado. Efeito linear crescente do consumo de proteína sobre o ganho em peso de ovinos foi observado no trabalho de Zundt et al. (2002), que avaliaram o desempenho de cordeiros alimentados com diferentes teores protéicos. 
Tabela 2. Médias e respectivos coeficientes de variação (CV) dos pesos vivos inicial (PVI) e final (PVF) e dos ganhos médios diários em peso vivo (GMD), em função dos tratamentos.

\begin{tabular}{|c|c|c|c|c|c|}
\hline \multirow{2}{*}{ Item } & \multicolumn{4}{|c|}{ Tratamento* } & \multirow{2}{*}{$\mathrm{CV}(\%)$} \\
\hline & SM & SMU & SP & $\mathrm{CO}$ & \\
\hline PVI (kg) & 20,52 & 20,95 & 20,12 & 20,75 & 12,25 \\
\hline PVF (kg) & $21,92^{\mathrm{ab}}$ & $21,27^{\mathrm{ab}}$ & $20,03^{b}$ & $24,17^{\mathrm{a}}$ & 10,12 \\
\hline GMD (g/dia) & $9,67^{\mathrm{b}}$ & $9,33^{\mathrm{b}}$ & $11,33^{\mathrm{b}}$ & $42,67^{\mathrm{a}}$ & 62,56 \\
\hline
\end{tabular}

a,b,c Valores seguidos por letras minúsculas diferentes na mesma linha diferem $(\mathrm{P}<0,05)$ entre si pelo teste de Student Neuman Keuls. *Tratamento - SM: Suplemento mineral; SMU: Suplemento mineral com ureia; SP: Suplemento proteinado; CO: Suplemento concentrado.

Fonte: Elaboração dos autores.

O peso de carcaça quente (PCQ) e o rendimento de carcaça quente (RCQ), em relação ao peso vivo final, foram influenciados pelos suplementos, sendo observados maiores valores para ambas variáveis no suplemento concentrado em relação aos demais, que não diferiram entre si (Tabela 3). Estes resultados, de certa forma, seguem a mesma tendência observada para o ganho médio diário em peso vivo e do peso vivo final dos animais nos diversos tratamentos. Landim (2005) e Menezes et al. (2008) reportaram altas correlações entre o peso vivo final e o peso de carcaça quente, de 0,94 e 0,99, respectivamente.

Dantas et al. (2008) avaliando características da carcaça de ovinos Santa Inês terminados em pastejo e submetidos a diferentes níveis $(0 ; 1,0$ e 1,5\% do peso vivo) de suplementação com concentrado obtiveram maior peso ao abate de animais suplementados com concentrado, verificando assim aumento no peso de carcaça quente e no rendimento de carcaça quente com alimentação com maiores quantidades de concentrado. Já Voltolini et al. (2010) usando misturas múltiplas com quatro teores $(5,8,11$ e 14\%) de ureia no concentrado para cordeiros mantidos em pastagem de capim Búffel verificaram que os suplementos não influenciaram o peso ao abate.

O rendimento de carcaça quente em relação ao peso de corpo vazio não foi influenciado pelos tratamentos (Tabela 3), demonstrando que ao se eliminar o efeito do peso do conteúdo gastrintestinal, não se observou diferenças quanto ao rendimento de carcaça dos diferentes tratamentos. Pode-se inferir, desse modo, que animais alimentados com suplemento concentrado, comparativamente aos animais dos demais suplementos, apresentaram menores conteúdos de digesta no trato gastrintestinal por ocasião do abate. Esse fato se consubstancia com o menor consumo de fibra em detergente neutro verificado com o suplemento concentrado (2,43\% do PV) em relação aos demais suplementos, que foi de 2,$95 ; 3,10$ e $2,94 \%$ do peso vivo, para os suplementos mineral, mineral com ureia e proteinado, respectivamente. Os resultados encontrados corroboram a asserção de que o rendimento de carcaça calculado em relação ao peso de corpo vazio é mais consistente do que em relação ao peso vivo, isto em função da variação que o peso do conteúdo gastrintestinal está suscetível. Essa variação pode decorrer da influência do tempo em jejum dos animais antes do abate, da raça, do tipo da dieta, do sexo, do peso ao abate e/ou idade e do grau de engorda. 
Tabela 3. Médias e respectivos coeficientes de variação (CV) de peso de carcaça quente (PCQ), rendimento verdadeiro (RCQ/PVF), rendimento biológico (RCQ/PCV), e pesos e rendimentos de cortes cárneos, em função dos tratamentos.

\begin{tabular}{|c|c|c|c|c|c|c|}
\hline \multirow{2}{*}{\multicolumn{2}{|c|}{ Item }} & \multicolumn{4}{|c|}{ Tratamento* } & \multirow{2}{*}{$\mathrm{CV}(\%)$} \\
\hline & & SM & SMU & SP & $\mathrm{CO}$ & \\
\hline \multicolumn{2}{|c|}{ PCQ (kg) } & $6,51^{b}$ & $6,14^{b}$ & $5,98^{b}$ & $8,39^{a}$ & 10,58 \\
\hline \multicolumn{2}{|c|}{ RCQ/PVF (\%) } & $29,79^{b}$ & $28,80^{\mathrm{b}}$ & $29,93^{b}$ & $34,74^{\mathrm{a}}$ & 6,05 \\
\hline \multicolumn{2}{|c|}{ RCQ/PCV (\%) } & 43,93 & 43,57 & 42,60 & 46,34 & 5,46 \\
\hline \multirow{2}{*}{ Perna } & $(\mathrm{kg})$ & $1,12^{b}$ & $1,09^{\mathrm{b}}$ & $1,10^{\mathrm{b}}$ & $1,48^{\mathrm{a}}$ & 12,02 \\
\hline & $(\%)$ & 35,87 & 36,02 & 36,74 & 35,88 & 3,21 \\
\hline \multirow{2}{*}{ Lombo } & $(\mathrm{kg})$ & $0,20^{\mathrm{b}}$ & $0,20^{\mathrm{b}}$ & $0,19^{b}$ & $0,29^{\mathrm{a}}$ & 17,27 \\
\hline & $(\%)$ & 6,36 & 6,46 & 6,42 & 6,95 & 12,32 \\
\hline \multirow{2}{*}{ Costilhar } & $(\mathrm{kg})$ & $0,47^{b}$ & $0,46^{\mathrm{b}}$ & $0,49^{b}$ & $0,63^{\mathrm{a}}$ & 18,77 \\
\hline & $(\%)$ & 14,79 & 15,18 & 16,46 & 14,92 & 15,64 \\
\hline \multirow{2}{*}{ Serrote } & $(\mathrm{kg})$ & $0,28^{\mathrm{b}}$ & $0,27^{b}$ & $0,26^{\mathrm{b}}$ & $0,43^{\mathrm{a}}$ & 21,02 \\
\hline & $(\%)$ & 9,05 & 9,08 & 8,74 & 9,85 & 12,07 \\
\hline \multirow{2}{*}{ Pescoço } & $(\mathrm{kg})$ & $0,290^{\mathrm{b}}$ & $0,293^{\mathrm{b}}$ & $0,316^{\mathrm{b}}$ & $0,433^{\mathrm{a}}$ & 15,13 \\
\hline & $(\%)$ & 9,26 & 9,60 & 10,6 & 10,22 & 9,96 \\
\hline \multirow{2}{*}{ Paleta } & (kg) & $0,65^{\mathrm{b}}$ & $0,65^{\mathrm{b}}$ & $0,65^{\mathrm{b}}$ & $0,87^{\mathrm{a}}$ & 12,17 \\
\hline & $(\%)$ & 20,62 & 21,26 & 21,89 & 21,16 & 6,07 \\
\hline
\end{tabular}

a,b,c Valores seguidos por letras minúsculas diferentes na mesma linha diferem $(\mathrm{P}<0,05)$ entre si pelo teste de Student Neuman Keuls. *Tratamento - SM: Suplemento mineral; SMU: Suplemento mineral com ureia; SP: Suplemento proteinado; CO: Suplemento concentrado.

Fonte: Elaboração dos autores.

Os valores observados de rendimento de carcaça quente para os diversos suplementos denotaram que o abate de ovinos mestiços Santa Inês com $25,0 \mathrm{~kg}$ de peso vivo proporciona carcaças com baixo rendimento. Garcia, Costa e Monteiro (2003), verificaram rendimento de carcaça quente de $51,1 \%$ em cordeiros da raça Suffolk terminados em confinamento abatidos com $31 \mathrm{~kg}$ de peso vivo. Lombardi et al. (2010) encontraram rendimento de carcaça quente de $48,63 \%$ para animais cruzados Hampshire Down-SRD (sem raça definida), com $31,05 \mathrm{~kg}$ de peso vivo ao abate. Araújo Filho et al. (2010) avaliando características de carcaça de animais das raças Morada Nova, Santa Inês e cruzados Dorper-Santa Inês observaram rendimentos de carcaça de 49,92; 47,22 e 47,98\%, respectivamente, para animais abatidos com peso médio de aproximadamente de $29 \mathrm{~kg}$.

Os maiores rendimentos de carcaça quente em relação ao peso vivo observados nos animais alimentados com o suplemento concentrado refletiram em maiores rendimentos de corte cárneos em valores absolutos $(\mathrm{kg})$, comparativamente aos demais tratamentos, que não diferiram entre si (Tabela 3). De acordo com Menezes et al. (2008), os cortes comerciais são altamente correlacionados com o peso vivo final, que no presente trabalho foi maior para os animais do tratamento concentrado. Os rendimentos dos cortes cárneos como porcentagem da carcaça não foram influenciados pelos tratamentos, demonstrando que todos os cortes comerciais evoluíram em peso em proporções semelhantes.

Carvalho et al. (2006) avaliando o desempenho e características da carcaça de cordeiros mantidos em pastagem de capim-tifton 85 e suplementados com diferentes teores de concentrado observaram que os pesos de quarto, paleta, costilhar e pescoço, expressos em $\mathrm{kg}$, aumentaram linearmente, com o aumento do teor suplementar. Dantas et al. (2008) avaliando as características da carcaça de ovinos Santa Inês terminados em pastejo e submetidos a 
diferentes níveis de suplementação na dieta $(0 ; 1,0$ e $1,5 \%$ do peso vivo) observaram aumento no peso dos cortes comerciais (perna, lombo, costilhar e paleta) no nível mais elevado de suplemento. De maneira contrária, Voltolini et al. (2010) avaliando misturas múltiplas com quatro teores $(5,8,11$ e 14\%) de ureia no concentrado para cordeiros mantidos em pastagem com capim-búffel, verificaram que os suplementos não influenciaram no peso e no rendimento dos cortes avaliados (pernil, paleta carré e costela).

Os tratamentos não influenciaram os componentes não-carcaça (Tabela 4). Com relação aos valores percentuais do trato gastrintestinal vazio e do conjunto coração, fígado, pulmão, rins e língua, diferenças seriam esperadas caso existissem diferenças de consumo de matéria seca em porcentagem do peso vivo entre os tratamentos, fato não observado no presente trabalho. Nesse sentido, Alves (2003) em uma consistente revisão sobre o crescimento compensatório, salientou que em período de restrição nutricional ocorre redução no tamanho dos órgãos internos em termos de peso vivo, ou seja, o crescimento dos mesmos, principalmente fígado e intestinos, é mais afetado do que o crescimento do animal como um todo (tendência a crescimento alométrico negativo). Já no caso do conjunto cabeça, pés e couro, diferenças podem ser associadas a grupos genéticos distintos.

Tabela 4. Porcentagens e respectivos coeficientes de variação (CV) de trato gastrintestinal vazio (TGIVZ), conjunto cabeça-pés-couro (CAPECO), coração-fígado-pulmão-rins-língua (CFPRL), expressos em relação ao peso corporal vazio, em função dos tratamentos.

\begin{tabular}{|c|c|c|c|c|c|}
\hline \multirow{2}{*}{ Item } & \multicolumn{4}{|c|}{ Tratamento* } & \multirow{2}{*}{$\mathrm{CV}(\%)$} \\
\hline & SM & SMU & SP & $\mathrm{CO}$ & \\
\hline TGIVZ (A) & 11,0 & 11,23 & 10,69 & 10,58 & 7,84 \\
\hline CAPECO (B) & 20,77 & 20,29 & 19,90 & 10,59 & 6,58 \\
\hline CFPRL (C) & 4,58 & 5,07 & 5,22 & 5,36 & 11,56 \\
\hline$(\mathrm{A}+\mathrm{B}+\mathrm{C})$ & 36,35 & 36,60 & 35,80 & 35,53 & 4,88 \\
\hline
\end{tabular}

${ }^{a, b, c}$ Valores seguidos por letras minúsculas diferentes na mesma linha diferem $(\mathrm{P}<0,05)$ entre si pelo teste de Student Neuman Keuls. *Tratamento - SM: Suplemento mineral; SMU: Suplemento mineral com ureia; SP: Suplemento proteinado; CO: Suplemento concentrado.

Fonte: Elaboração dos autores.

Alves et al. (2003) trabalhando com teores de 2,42; 2,66; e 2,83 Mcal de energia metabolizável/ $\mathrm{kg}$ de MS para ovinos verificaram que não houve influência dos teores enegéticos no peso do trato gastrintestinal. Carvalho e Medeiros (2010) observaram que os componentes não-carcaça pele, patas, cabeça e coração, assim como os rins, fígado, pulmão + traqueia e baço não foram influenciados pelos teores de energia $(1,49 ; 1,55 ; 1,62 ;$ ou 1,68 Mcal de energia líquida/kg MS) estudados.

Clementino et al. (2007) avaliando crescentes teores $(30,45,60$ e $75 \%)$ de concentrado na ração para cordeiros confinados observaram que os componentes sangue, fígado, rins, brônquios + pulmões, baço e coração apresentaram aumento de peso médio quando elevaram o teor de concentrado na ração.

Entre as medidas morfométricas avaliadas, apenas a largura de peito (medida morfométrica in vivo) e perímetro de perna (medida morfométrica na carcaça) foram maiores para o suplemento concentrado (Tabela 5), indicando que essas medidas podem ser utilizadas na predição do peso vivo final ao abate, haja vista o maior peso vivo ao abate para os animais alimentados com o suplemento concentrado em relação aos demais, que não diferiram entre si. 
Tabela 5. Médias e respectivos coeficientes de variação $(\mathrm{CV})$ das medidas morfométricas $(\mathrm{cm})$ in vivo e na carcaça e respectivos coeficientes de variação $(\mathrm{CV})$ em função dos tratamentos.

\begin{tabular}{|c|c|c|c|c|c|}
\hline \multirow{2}{*}{ Medida morfométrica } & \multicolumn{4}{|c|}{ Tratamento* } & \multirow{2}{*}{$\mathrm{CV}(\%)$} \\
\hline & SM & SMU & SP & $\mathrm{CO}$ & \\
\hline & \multicolumn{4}{|c|}{ In vivo } & \\
\hline Comprimento do corpo & 56,10 & 56,50 & 55,40 & 56,30 & 6,48 \\
\hline Comprimento horizontal do corpo & 49,80 & 51,30 & 50,00 & 51,10 & 5,40 \\
\hline Altura de cernelha & 59,50 & 60,40 & 59,83 & 58,10 & 5,01 \\
\hline Altura do sacro & 60,50 & 62,10 & 61,33 & 61,02 & 4,25 \\
\hline Altura do peito & 34,80 & 35,40 & 35,92 & 34,00 & 6,56 \\
\hline Altura do tórax & 24,92 & 25,28 & 24,36 & 24,76 & 5,16 \\
\hline Largura de peito & $14,40^{\mathrm{b}}$ & $14,67^{\mathrm{b}}$ & $14,50^{\mathrm{b}}$ & $15,53^{\mathrm{a}}$ & 3,76 \\
\hline Largura do ílio & 10,38 & 11,57 & 11,60 & 11,10 & 9,27 \\
\hline Largura do ísquio & 8,92 & 8,92 & 9,20 & 8,90 & 5,59 \\
\hline \multirow[t]{2}{*}{ Perímetro Torácico } & 67,40 & 64,70 & 63,75 & 67,80 & 4,38 \\
\hline & \multicolumn{4}{|c|}{ Carcaça } & \\
\hline Comprimento externo da carcaça & 53,50 & 53,70 & 50,90 & 52,3 & 6,53 \\
\hline Largura da garupa & 13,40 & 13,17 & 13,17 & 13,52 & 3,31 \\
\hline Largura do tórax & 22,10 & 21,30 & 21,50 & 22,30 & 10,25 \\
\hline Perímetro de garupa & 44,30 & 43,50 & 43,20 & 47,00 & 5,74 \\
\hline Perímetro de perna & $28,80^{\mathrm{b}}$ & $28,40^{\mathrm{b}}$ & $28,08^{\mathrm{b}}$ & $32,30^{\mathrm{a}}$ & 5,72 \\
\hline Comprimento interno da carcaça & 54,30 & 54,70 & 55,40 & 55,80 & 4,19 \\
\hline Comprimento da perna & 36,30 & 38,40 & 37,25 & 36,60 & 4,13 \\
\hline
\end{tabular}

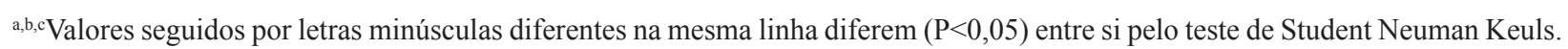
*Tratamento - SM: Suplemento mineral; SMU: Suplemento mineral com ureia; SP: Suplemento proteinado; CO: Suplemento concentrado.

Fonte: Elaboração dos autores.

Souza et al. (2010) avaliando o desempenho produtivo e parâmetros de carcaça de cordeiros mantidos em pastos irrigados e suplementados com doses crescentes de concentrado, verificaram aumento no comprimento externo da carcaça, perímetro da garupa, perímetro do pernil, na largura de pernil, largura do tórax e na profundidade do tórax, para os ovinos que receberam maior dose do suplemento.

Na Tabela 6 são apresentadas as correlações que apresentaram significância entre as variáveis ganho médio diário em peso vivo (GMD), rendimento de carcaça quente em relação ao peso vivo (RCQ/ $\mathrm{PV})$ e em relação ao peso de corpo vazio (RCQ/
PVZ) e as variáveis morfométricas determinadas nas carcaças. Deve-se ressaltar que as variáveis GMD, RCQ/PV e RCQ/PVZ, não apresentaram correlações significativas com nenhuma das variáveis morfométricas determinadas in vivo, à exceção do perímetro torácico, que correlacionou $(r=0,48)$ com GMD. Pode-se inferir, desse modo, que mensurações na carcaça podem ser utilizadas com maior precisão na predição do ganho médio diário em peso vivo e de rendimentos de carcaça, destacando-se as mensurações na carcaça de largura de peito, perímetro de garupa e perímetro de perna, que apresentaram correlações significativas com todas as variáveis (GMD, RCQ/PV e RCQ/PVZ). 
Tabela 6. Correlações entre as variáveis ganho médio diário em peso vivo (GMD), rendimento de carcaça quente em relação ao peso vivo (RCQ/PV) e em relação ao peso de corpo vazio (RCQ/PVZ).

\begin{tabular}{lcc}
\hline \multicolumn{1}{c}{ Variável } & Variável & Correlação* \\
\hline GMD & LT & 0,72 \\
GMD & PET & 0,48 \\
GMD & PG & 0,50 \\
GMD & PP & 0,68 \\
GMD & CIC & 0,36 \\
RCQ/PV & LP & 0,49 \\
RCQ/PV & PG & 0,39 \\
RCQ/PV & PP & 0,56 \\
RCQ/PVZ & LP & 0,43 \\
RCQ/PVZ & LG & 0,37 \\
RCQ/PVZ & PG & 0,37 \\
RCQ/PVZ & PP & 0,48 \\
\hline
\end{tabular}

$\mathrm{LT}=$ largura do tórax $; \mathrm{PET}=$ perímetro de tórax $; \mathrm{PG}=$ perímetro da garupa; $\mathrm{PP}=$ perímetro de perna $; \mathrm{CIC}=$ comprimento interno da carcaça; $\mathrm{LG}=$ largura da garupa

*Correlação de Pearson, significativo em nível de 5\% pelo teste t. Fonte: Elaboração dos autores.

Para Wood et al. (1980), o comprimento interno da carcaça é bom indicador de peso e características de carcaças. Bueno et al. (2000) avaliando características de carcaça de cordeiros Suffolk abatidos com diferentes idades observaram que as medidas de comprimento interno da carcaça, profundidade torácica, comprimento e perímetro de perna e largura da garupa mostraram relação linear positiva com a idade ao abate. Nesse trabalho, o peso dos animais aumentou em função da idade, isto é, quanto mais erados mais pesados foram os cordeiros.

\section{Conclusões}

$\mathrm{O}$ fornecimento de suplemento concentrado para ovinos na proporção de $0,8 \%$ do peso vivo, possibilitou maiores peso vivo final, ganho médio diário em peso vivo, peso de carcaça quente, rendimento de carcaça quente em relação ao peso vivo final e rendimento de cortes cárneos, em quilogramas, em relação aos suplementos mineral, mineral com ureia e proteinado.
Os percentuais dos componentes não-carcaça não são influenciados pelas diferentes estratégias de suplementação.

O suplemento concentrado aumentou a largura de peito e o perímetro de perna em ovinos, medidas mensuradas in vivo e na carcaça, respectivamente.

As mensurações morfométricas na carcaça podem ser utilizadas com maior precisão na predição do ganho médio diário em peso vivo e do rendimento de carcaça quente que medidas morfométricas in vivo, destacando-se a largura de tórax e os perímetros de garupa e de perna.

\section{Agradecimentos}

Ao Conselho Nacional de Desenvolvimento Científico e Tecnológico (CNPq) pelo financiamento do projeto de pesquisa, à Coordenação de Aperfeiçoamento de Pessoal de Nível Superior (CAPES) e à Fundação de Amparo à Pesquisa do Estado de Minas Gerais (FAPEMIG) pela concessão de bolsas e apoio financeiro.

\section{Referências}

ALVES, D. D. Crescimento compensatório em bovinos de corte. Revista Portuguesa de Ciências Veterinárias, Lisboa, v. 98, n. 546, p. 61-67, 2003.

ALVES, K. S.; CARVALHO, F. F. R.; FERREIRA, M. A.; VÉRAS, A. S. C.; MEDEIROS, A. N.; NASCIMENTO, J. F.; NASCIMENTO, L. R. S.; ANJOS, A. V. A. Níveis de energia em dietas para ovinos Santa Inês: características de carcaça e constituintes corporais. Revista Brasileira de Zootecnia, Viçosa, MG, v. 32, n. 6, p. 1927-1936, 2003. Suplemento 2 .

ARAÚJO FILHO, J. T.; COSTA, R. G.; FRAGA, A. B.; SOUSA, W. H.; CEZAR, M. F.; BATISTA, A. S. M. Desempenho e composição da carcaça de cordeiros deslanados terminados em confinamento com diferentes dietas. Revista Brasileira de Zootecnia, Viçosa, MG, v. 39, n. 2, p. 363-371, 2010.

BUENO, M. S.; CUNHA, E. A.; SANTOS, L. E.; SANCHEZ RODA, D.; LEINZ, F. F. Características de carcaça de cordeiros Suffolk abatidos em diferentes idades. Revista Brasileira de Zootecnia, Viçosa, MG, v. 29, n. 6, p. 1803-1810, 2000. 
CARVALHO, S.; BROCHIER, M. A.; PIVATO, J.; TEIXEIRA, R. C.; KIELING, R. Ganho de peso, características da carcaça e componentes não-carcaça de cordeiros da raça Texel terminados em diferentes sistemas alimentares. Ciência Rural, Santa Maria, v. 37, n. 3, p. 821-827, 2007.

CARVALHO, S.; MEDEIROS, L. M. Características de carcaça e composição da carne de cordeiros terminados em confinamento com dietas com diferentes níveis de energia. Revista Brasileira de Zootecnia, Viçosa, MG, v. 39, n. 6, p. 1295-1302, 2010.

CARVALHO, S.; VERGUEIRO, A.; KIELING, R.; TEIXEIRA, R. C.; PIVATO, J.; VIERO, R.; CRUZ, A. N. Desempenho e características da carcaça de cordeiros mantidos em pastagem de tifton- 85 e suplementados com diferentes níveis de concentrado. Revista Brasileira de Agrociência, Pelotas, v. 12, n. 3, p. 357-361, 2006.

CEZAR, M. F.; SOUSA, W. H. Carcaças ovinas e caprinas: obtenção-avaliação-classificação. Uberaba: Agropecuária Tropical, 2007. 232 p.

CLEMENTINO, R. H.; SOUSA,W. H.; MEDEIROS, A. N.; CUNHA, M. das G. G.; GONZAGA NETO, S.; CARVALHO, F. F. R. de; CAVALCANTE, M. A. B. Influência dos níveis de concentrado sobre os cortes comerciais, os constituintes não-carcaça e os componentes da perna de cordeiros confinados. Revista Brasileira de Zootecnia, Viçosa, MG, v. 36, n. 3, p. 681688, 2007.

DANTAS, A. F.; PEREIRA FILHO, J. M.; SILVA, A. M. A.; SANTOS, E. M.; SOUSA, B. B.; CEZAR, M. F. Características da carcaça de ovinos Santa Inês terminados em pastejo e submetidos a diferentes níveis de suplementação. Ciência e Agrotecnologia, Lavras, v. 32, n. 4, p. 1280-1286, 2008.

FURUSHO-GARCIA, I. F.; PEREZ, J. R. O.; TEXEIRA, J. C. Componentes de carcaça e composição de alguns cortes de cordeiros Texel $\times$ Bergamácia, Textel $\times$ Santa Inês e Santa Inês puros, terminados em confinamento, com casca de café como parte da dieta. Revista Brasileira de Zootecnia, Viçosa, MG, v. 32, n. 6, p. 1999-2006, 2003.

GARCIA, C. A.; COSTA, C.; MONTEIRO, A. L. G. Níveis de energia no desempenho e característica da carcaça de cordeiros alimentados em creep feeding. Revista Brasileira de Zootecnia, Viçosa, MG, v. 32, n. 6, p. 1371-1379, 2003.

LANDIM, A. V. Desempenho e qualidade de carcaça em ovinos cruzados no Distrito Federal. 2005. Dissertação (Mestrado em Ciências Agrárias) - Faculdade de Agronomia e Medicina Veterinária - Universidade de Brasília, Brasília.
LOMBARDI, L.; JOBIM, C. C.; BUMBIERIS JÚNIOR, V. H.; CALIXTO JÚNIOR M.; MACEDO, F. A. F. Características da carcaça de cordeiros terminados em confinamento recebendo silagem de grãos de milho puro ou com adição de girassol ou ureia. Acta Scientiarum Animal Sciences, Maringá, v. 32, n. 3, p. 263-269, 2010.

MARTINEZ, D. E.; NUÑEZ, F. A. G.; GARCÍA, A. M.; BLANCA, A. T. Caracterización de canales de borregos alimentados con desechos de papel. Revista Brasileira de Agrociência, Pelotas, v. 7, n. 1, p. 50-53, 2001.

MENEZES, L. F. O.; LOUVANDINI, H.; MARTHA JÚNIOR, G. B.; MCMANUS, C.; GARCIA J. A. S.; MURATA, L. S. Características de carcaça, componentes não-carcaça e composição tecidual e química da $12^{\mathrm{a}}$ costela de cordeiros Santa Inês terminados em pasto com três gramíneas no período seco. Revista Brasileira de Zootecnia, Viçosa, MG, v. 37, n. 7, p. 1286-1292, 2008.

PINHEIRO, R. S. B.; SILVA SOBRINHO, A. G.; MARQUES, C. A. T.; YAMAMOTO, S. M. Biometria in vivo e da carcaça de cordeiros confinados. Archivos de Zootecnia, Córdoba, v. 56, n. 216, p. 955-958, 2007.

RUIZ DE HUIDOBRO, F.; CAÑEQUE, V. Produccion de carne de corderos de raza Manchega. 5. Crecimiento relativo del quinto cuarto y de los tejidos y piezas de la canal. Investigacion Agraria: Produccion y Sanidad Animales, Madrid, v. 9, n. 2, p. 95-108, 1994.

SILVA SOBRINHO, A. G. Criação de ovinos. 2. ed. Jaboticabal: FUNEP, 2001. 302 p.

SILVA, D. S.; QUEIROZ, A. C. Análises de alimentos: métodos químicos e biológicos. 3. ed. Viçosa: UFV, 2002. $235 \mathrm{p}$.

SILVA, L. F.; PIRES, C. C. Avaliações quantitativas das proporções de osso, músculo e gordura da carcaça em ovinos. Revista Brasileira de Zootecnia, Viçosa, v. 29, n. 4, p. 1253-1260, 2000.

SILVA, N. V. da; SILVA, J. H. V. da; COELHO, M. de S.; OLIVEIRA, E. R. A. de; ARAÚJO, J. de A.; AMÂNCIO, A. L. de L. Características de carcaça e carne ovina: uma abordagem das variáveis metodológicas e fatores de influência. Acta Veterinaria Brasilica, Mossoró, v. 2, n. 4, p. 103-110, 2008.

SIQUEIRA, E. R. Produção de carne de cordeiros. In: ENCONTRO MINEIRO DE OVINOCULTURA, 1., 2000, Lavras. Anais... Lavras: UFLA, 2000. p. 129-149.

SOUZA, R. A.; VOLTOLINI, T. V.; PEREIRA, L. G. R.; MORAES, S. A.; MANERA D. B.; ARAÚJO, G. G. L. Desempenho produtivo e parâmetros de carcaça de cordeiros mantidos em pastos irrigados e suplementados com doses crescentes de concentrado. Acta Scientiarum Animal Sciences, Maringá, v. 32, n. 3, p. 323-329, 2010. 
UNIVERSIDADE FEDERAL DE VIÇOSA - UFV. 2000. Sistema de análises estatísticas e genéticas. Versão 8.0. Viçosa, MG.

VOLTOLINI, T. V.; MORAES, S. A.; ARAÚJO, G. G. L.; OLIVEIRA, P. L. T.; PEREIRA, L. G. R. Urea levels in multiple supplement for lambs grazing on buffelgrass. Acta Scientiarum. Animal Sciences, Maringá, v. 32, n. 4, p. 461-465, 2010.
WOOD, J. D.; MACFIE, H. J. H.; POMERY, R. W.; TWINN, D. J. Carcass composition in four sheep breeds: The importance of breed and stage of maturity. Animal Production, Cambridge, v. 30, n. 1, p. 135-152, 1980.

ZUNDT, M.; MACEDO, F. A. F.; MARTINS, E. N.; MEXIA, A. A.; YAMAMOTO, S. M. Desempenho de cordeiros alimentados com diferentes níveis protéicos. Revista Brasileira Zootecnia, v. 31, n. 3, p. 1307-1314, 2002. 